\title{
حقيبة تعليمية إلكترونية وتاثيرها على تعلم سباحة الزحف على الصدر
}

محمد فتحى بيومى ابر اهيم'

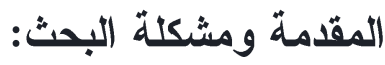

يشهد عصرنا الحالي طفرة هائلة في ظهور المستحدثات التكنولوجية المرتبطة بالعملية التعليمية لذلك ظهرت الحاجة إلى توظيف تلك المستحدثات التكنولوجية و الاستفادة منها في التعليم، وتطــوير أداء المعلم والمتعلم حيث يقع العبء الأكبر على العنصر البشري في توظيف التكنولوجيا و لابد مسن استثمار هذه العقول البشرية وذالك بتطويرها وبناءها وتجديدها بما يتتاسب مع مستحدثات تكنولوجيا Electronic التعليم حيث ظهرت عديد من المصطلحات و التي منها الحقائب التعليمية الإلكترونيـــة instructional packages خبرات ومهار ات الوسائط المتعددة الإلكترونية. (1: Y I) ويري محمد محمد الحاحمي (T . . rم) أن النظور الكبير في تقنية الاتصالات و المعلومسات ، و انتشار المعرفة الالكترونية بين طلاب الددارس و الجامعات إلى ظهور اشكال جديدة من نظم التعليه، ففي العقد الماضي ظهرت أدوات التعليم و التدريب المعتمدة على الحاسوب بشكل رئيسـي و علـى أساليب التفاعل المختلفة معه مستقيدة من الأقراص المضغوطة و الثبكات المحلية وخـلال القــرن الحالي تطور مفهوم التعليم الالكتروني وتميزت أدو اته باستعمال الانترنت، أما هذه الأيام فيلوح فـي الأفق القريب إمكانيات استثمار تقنية الاتصالات اللاسلكية عامة و النقالة خاصة ليظهر مفهوم جديد

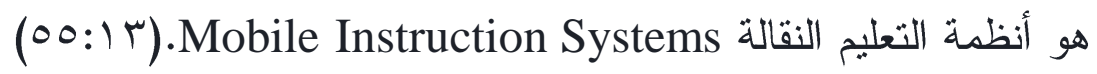
ويذكر جمال على الدهان (9 . . بم) الحقائب التعليمية الإلكترونية من أكثر النقليات الحديثــة التي يمكن توظيفها في المؤسسات و المر اكز التعليمية نظر الما تتمتع به من كفاءة وفاعلية يضــاف إلى ذلك أن الحقائب التعليمية الإكترونية تتركز على عدد من المبادئ الحديثة التي برهنت الدراسات المتعلقة بالتعليم الإنساني و البحوث المفصلة بتشكيل السلوك البشري على أهميتها ومن هذه المبادئ التي توظفها الحقيبة الإلكتزونية مبدأ التعليم الذاتي . 
ونظر التتوع الخبرات و النشاطات التي تتضمنها الحقيبة التعليمية الإلكترونية مـــواد مطبوعــة

و أشرطة تلفازية ، بشر ائح ناطقة ، أدلة لاستخدام الحقيبة من قبل المعلم و الـــتعلم مقــاطع فيــيو ،

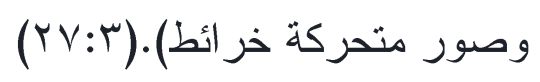

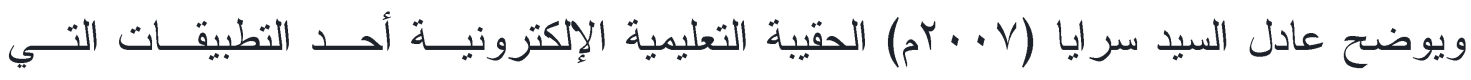

توفر للمتعلم أكثر من وسيلة للتعلم إضافة للمتعلم، طهــذا بطبيعـة الحــال سيســاهم فـي تحسـين

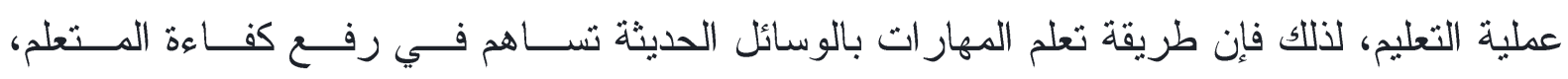

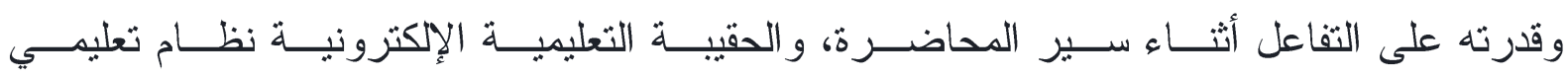

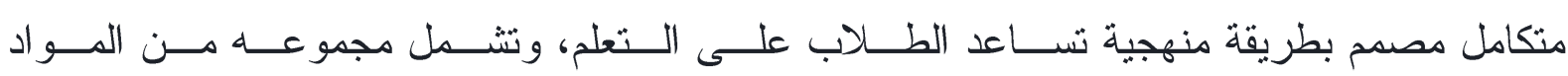

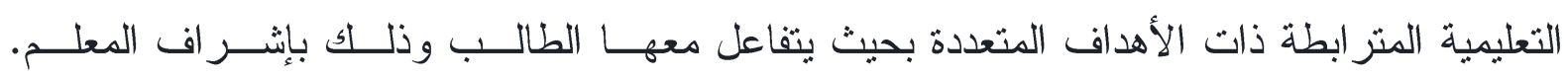

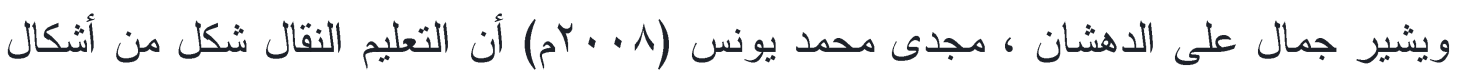
التعليم الإلكتروني ولكنه يعتمد على الأجهزة اللاسلكية متل الهو اتف النقالة، و الهو اتف الذكية، حيث أنه يهيئ فرصا عديدة لإحداث التفاعل وإجر اء التعليم التعاوني بين الطلاب وبعضهم و بين الطلاب و المعلم و الذي لا تحققه بعض الطرق الأخرى بهذه الكفاءة العالية ويتيح التعليم النقال للمتعلم إككانية التواصل السريع مع شبكة المعلومات في أي وقت و أي مكان كما يسهل عملية تبادل المعلومات بين المتعلمين و إرسال أستفسار اتهم للمعلم من خلال الرسائل، ويعتبر الحجم الصغير للاجهزة التي بــتم التعلم من خلالها أحد أهم ما يميزها ويسهل عملية التعليم من خلالها كما أن أسعار تلــــ الأجهـزة منخفضة نسبياً وفي متتاول معظم الطلاب و هذه الأجهزة سهلة الاستخدام و التنقل وذات قدرة تخزينية عالية ولذا يعتبر التعليم النقال ذات أثر إيجابي كبير في العملية التعليمية. (ع:ץ) أن من أسباب استخدام الهاتف المحمول في عمليات التعليم والتدريب عوامل منها النمو المتزايد الاستخدام الأجهزة النقالة عموما و الهو اتف المحمولة على وجه الخصوص في العالم كله حيــث زاد عدد مستخدميها بصورة كبيرة خاصة بعد أن أصبحت تقنية تلك الأجهزة رخيصة، فــالو اقع الحـالي يشير إلى أنه مع تتامي ثورة الاتصالات العالمية أصبح متاحاً لكل شخص امتلاك جهازه الـحهــول، وتعدد الخدمات التي يمكن أن تقدها الهواتف المحمولة في مجال التعليم والتنريس • (ب:ء) 
ويوضح محمد محمود الحيلة (T . . Tم) ان تقنيات التعليم المتعددة الوسائط للتطور بسرعة مــع تطور التكنولوجيا ومن ضمن هذه الوسائط المتعددة جهاز عرض البيانات و الفيديو (data show) و

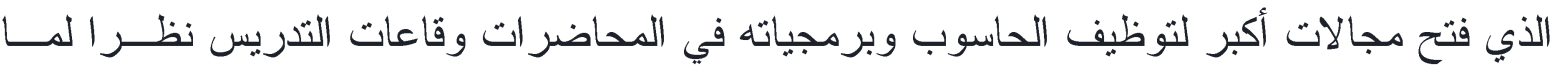
يتو افر فيه من مز ايا تقديم عروض مبتكرة بالصوت و الصــورة والحركسـة ذات الجـودة العاليــة.

لعبت مو اقع التواصل الاجتماعي (تويتر ، فيس بوك، يوتيوب) في العملية التعليمية دورا كبيرا في عملية التعليم و التثريس ، لأنها تعزز من ارتباط الطلاب بالمحيط المحلي و العالمي من حـولهم، وتجعلهم على وعي بكل ما يشهده العالم من مستجدات تقنية وعلمية وثقافية لذلك تسعى المؤسسـات التعليمية الانتقال من التعليم التقليدي الذي يعتمد على الكتاب المدرسي و الحفظ و التلقين إلى التعلــــم

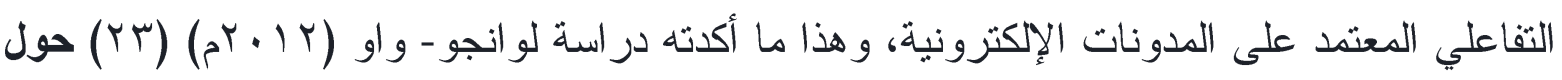
استخدام مواقع الفيس بوك كنظام متكامل في العملّية التعليمية و على أهمية مو اقع شبكات التو اصل الاجتماعي في عملية التعليم و التدريس من خلال تتظيم دروس أســبوعية مـــع إجــر اء الحـــوارات و المناقثات من خلال شبكة الأنترنت و استخلصت الدر اسة أن هناك ارتباح كبير اللطلبة لاســتخدام هذه المواقع من خلال الثبكات التكنولوجية المتقدمة

مثكلة البحث

لقد أصبحت الأجهزة التكنولوجية في الوقت الحالي من الأدوات التكنولوجيــة التــي لا تكــــاد تفارق مستخدميها في ليل أو نهار، و التي زاد عدد مستخدميها بصورة كبيرة، خاصة بعد أن أصبحت تقنية تلك الأجهزة رخيصة - سواء فيما تعلق بأسعار تللك الأجزة أو تكلفة الخدمات المرتبطة بها فالثقنيات المحمولة من مثل الهو اتف المحمولة الحواسيب المحمولة و الأجهزة الرقميــة الثخصـية personal digital كأحد أهم هذه الأجهزة واشهرها - من جهاز مكمل يقتصر استخدامه على فئة معينة من الأشخاص،

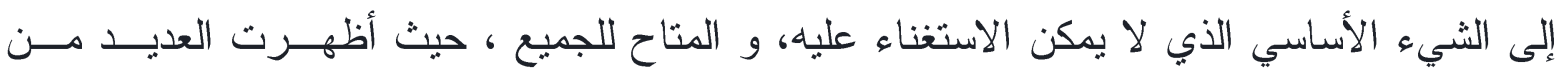
الدراسات أن الهاتف الدحمول هو أكثر الأجهزة التكنولوجية استخدام بين أيدينا. (ع (ب) 


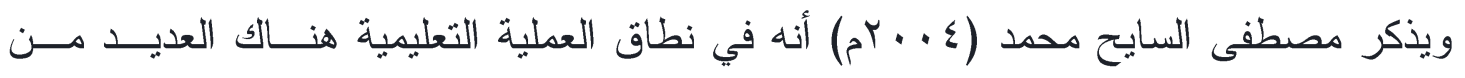

المشكلات ومن بينها صعوبة عملية التعليم و التدريس الطلاب و التي تعـزى إلـى ازديــاد أعــداد المتعلمين و إلى استخدام الطرق التقليدية في التدريس بما يؤدي إلى أن تتم العملية التعليمية في وقــت أطول وبجهد أكبر وقد لا تتحقق النتيجة المرجوة ، إلا أن ظهور التكنولوجيا بشكل عام ومن بينهـا تكنولوجيا التعليم (أو التقنيات التعليمية) بشكل خاص أدى إلى فاعلية نقل وتعليم المنـــاهج المقــررة سو اء كانت نظرية أو تطبيقية. (79:1 (Y (Y) ويوضح نبيل جاد عزمي (10 + rم) أن التعليم متاح في كافة مو اقف الحياة التي بها قدرا كافية من الشروط الملائمة للتعلم ، فالتعلم لا يحدث فقط في الفصول الدر اسية ولكن أيضا في كم متتوع من البيئات ، كما يحدد أيضاً على كافة المستويات (أفر اد وجماعات تتألف من كل الأحجام و التكوينـات و من مختلف التفافات). (0:IV)

ويشير محمد سعد زغلول ، مكارم حلمي أبو هرجة، هاني ســعيد عبــد المــنعم (1 . . rم) أن التربية الرياضية من حيث كونها معلومات وقو انين ومهار ات يجب إجادتها ، فهي أحوج ما تكـون لاستغلال كافة وسائل الثقدم العلمي من أساليب وتقنيات حديثه لكي تسهل على المعلم و على المــتعلم الوصول إلى الأهداف المرجوة ، حيث أصبحت الوسائل المتبعة في التعليم غير كافيـهـه ولا تحقـق

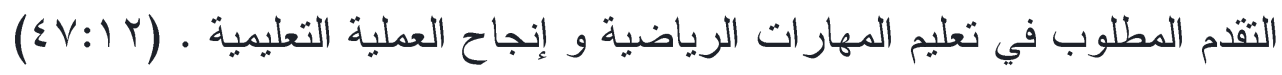
يذكر ماجليشيو " Maglischo"(r . . r م) إن سباحة الزحف على الصدر هى السباحة الأسهل فى عملية التنفس بين السباحات التنافسية الأربع ( الزحف على البطن و الصــدر وســباحة الصــدر وسباحة الفر اثة ) وتحتوى كل دورة ذراع لسباحة الزحف على الصدر حركة الذراع الأيمن وحركة

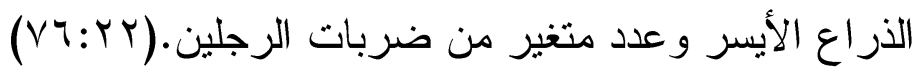

ومن خلال عمل الباحث كمعلم سباحة - لاحظ الباحث صعوبة في تعليم سباحة الزحـف علىى الصدر وينعكس ذلك على تحصيلهم التحليمى لسباحة الصدر ، ويعود ذلك إلى انتشار الطرق التقليدية في تعليم سباحة الزحف على الصدر ،إضافة لكونها من الرياضات صعبه الاستيعاب وتحتــاج إلـى قدر ات معينة ، ولغرض تلافي هذه المشكلة المتمتلة في الفجوة بين قدر ات المتعلم ومســتوي ســباحة الزحف على الصدر ـ فقد رأى الباحث إمكانية توظيف تقنيات التعليم، ومنها الحقائب الإلكترونية التي يمكن للمتعلم استخدامها داخل العملية التعليمية وخارجها، ولكون (الهاتف النقال - مواقــع التواصـلـ الاجتماعي - جهاز عرض البيانات Data Show) هي أدوات ووسائل تشجع المتعلم علـى الـتـعلم 
وكذلك تثر دافعيته نحو التعلم، وتبعد الملل مقارنة بالطرق السائدة في التعليم ، جاءت هذه الدراســة للكشف عن أثر الحقيبة التعليمية الإككترونية وتأثير ها على تعلم سباحة الزحف على الصدر كنوع من أنو اع تكنولوجيا التعليم باعتبار ها توفر الوقت و الجهد وتسهيل مهمة استيعاب المتعلم ـ ايضاً وقد وجد الباحث أن الاسلوب المتبعة (أسلوب الأوامر) في تعليم مهار ات سباحة الزحف على الصــدر، تعتـــــ على مصدر و احد و هو المعلم و الذي يقوم بالشرح من جانبه يتبعه عرض للنموذج دون أدنى مشاركة فعلية المتعلم في الموقف التعليمي وهذا لا يتلاءم مع التطور في تكنولوجيا التعليم من حيث استخدامها للارتقاء بالعملية التعليمية في الوقت الحاضر ، مما يؤكد على أن استخدام تكنولوجيا التعلــيم يحقــق أهداف العملية التعليمبة.

\section{أهمية البحث و الحاجة إليه :}

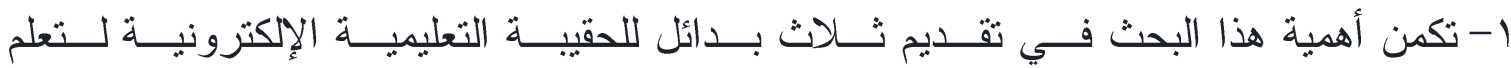

$$
\text { سباحة الزحف على الصدر وهما : }
$$

أ- الوسيلة التكنولوجية الأولى ( Mobil application و هو تطبيق على الموبايل يحتـوي علـى

$$
\text { مهار ات لتعلم سباحة الزحف على الصدر ) }
$$

ب-الوسيلة التكنولوجية الثانية ( كتيب الكترونى تعرض على data show وتحتوي على نصــوص وصور ثابتة وصور متحركة وفيديوهات متعلقة بتعليم سباحة الزحف على الصدر) ج- الوسيلة التكنولوجية الثالثة ( Secret Groups وهو مجمو عه سري على الفيس بوك ويحتـوي على مهار ات لتعلم سباحة الزحف على الصدر ويتم عرض الوحدات التعليمية بتسلسل و استمر ارية العرض ويقوم الباحث بالإشر اف والتوجيه لجميع المتعلمين على المجموعه و الرد على تسـاؤلاتهم وتعليقاتهخ )

Y- قد يسهم هذا البحث في الكثف عن وسائلٍ وبدائل تكنولوجية جديدة في عملية التعليم وذلــك بالتركيز على المتعلم من خلال تطبيق الوسائل التكنولوجية الحديثة r-يمكن أن يشجع هذا البحث الباحثين ومصممي البرامج الحاسوبية وتطبيقات الموبايل التعليمية على توظيف العملية المنظمة للتصميم التعليمي في تصميم البرامج الحاسوبية وكذلك تطبيقات الموبايل التعليمية و إنتاجها و استخدامها. 
ع - قد يكثف هذا البحث بعض المعوقات الفعلية التي تحد من استخدام برامج وتطبيقات الموبايــلـ

.Mobile application

0- و يستفيد الباحثون و المعلمون في مجال التدريس و التعليم عامة وللرياضات المائية خاصــة

لأهمية الحقيبة التعليمية الإلكتزونية وتأثير ها على تعلم سباحة الزحف على الصدر.

هاف البحث

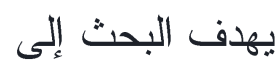

1-معرفة تاثير برنامج تعليمي بإستخدام الحقيبة التعليمية الإلكترونية على تعلم سباحة الزحسف

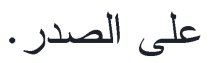

ץ- دراسة فاعلية استخدام ( تطبيق الموبايل Mobile application و الكتيب الالكترونى - و

المجموعه السري Secret Groups على موقع التواصل الاجتماعي فيس بوك ) على تعلـــم

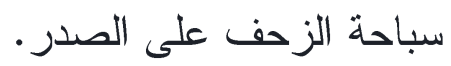

ب- الوقوف على الفرق بين فاعلية الحقيبة التعليمية باستخدام ثلاث وسائل تكنولوجيــة و التعلــيم

التقليدي المتبع فى عملية تعليم السباحة .

ع- الخروج بتوصيات ومقترحات قد تساع الباحثين بصفة عامة و معلمـين ومــدربين الســباحة

بصفة خاصة على تفعيل استخدام الموبايل وتطبيقاته - و البر امج الحاسوبية - وتفعيل الــدور

الإيجابي في العملية النعليمية لمو اقع التو اصل الاجتماعي وخاصة الفيس بوك.

فروض البحث

في ضوء أهداف البحث يفترض الباحث ما يلي

ا-توجد فروق دالة إحصائيا بين متوسـطـي درجـات القيــاس القبلــي و البعـدي للمجموعــة

التجريبية في تعليم سباحة الزحف على الصدر ولصالح القياس البعدي

Y-توجد فروق دالة إحصائيا بين منوسـطـي درجـات القيــاس القبلــي و البعـدي للمجموعــة

الضابطة في تعليم سباحة الزحف على الصدر ولصالح القياس البعدي

ب- توجد فروق دالة إحصائية بين المجموعة التجريبيــة و المجموعــة الضــابطة فـي القيــاس

البعدي في تعليم سباحة الزحف على الصدر لصالح المجموعة التجريبية 
ع - توجد نسب تقدم لقياس البعدي لكل من المجموعة التجريبيــة و المجموعــة الضــابطة فـي تعليم سباحة الزحف على الصدر ولصالح المجموعة التجريبية.

المصطحات المستخدمة:

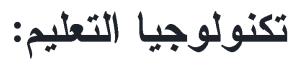

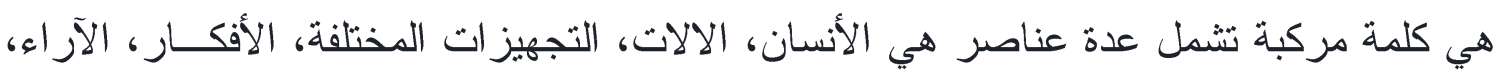
اساليب العمل وطرق الإدارة التحليل المشاكل و ابتكار وتتفيذ وتقويم و إدارة الحلول او العملية التي لتحاني

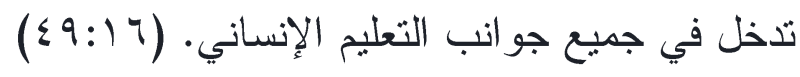

الحقيبة التعليمية الإكترونية:

نمط تعليمي متكامل ، مصدم باسلوب منهجي منظم يساعد المتعلمين علـى الـتـعلم بتزويــدهم

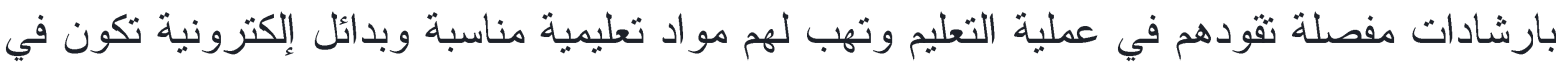

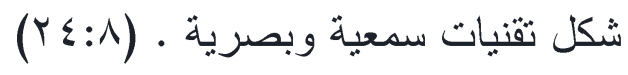

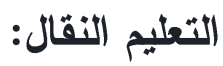

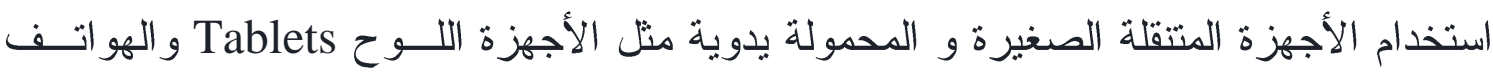

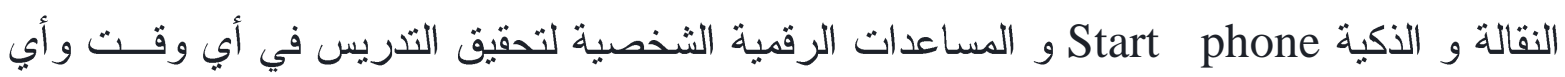

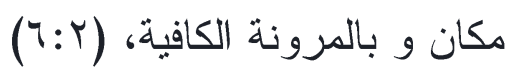

تطبيق المحمول: - n

النطبيق النقال Mobile application هو برنامج كمبيوتز مصمم ليعمل على الهو اتف الذكيــة

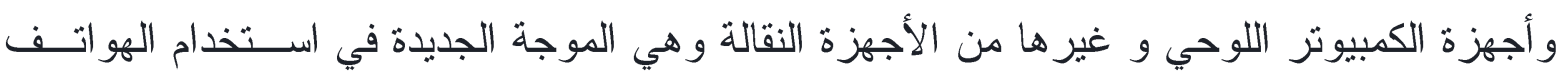

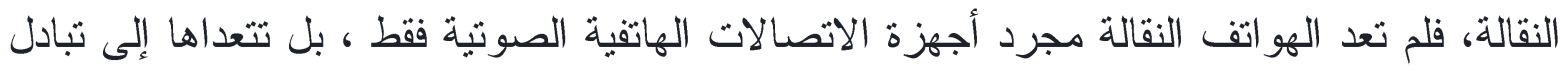

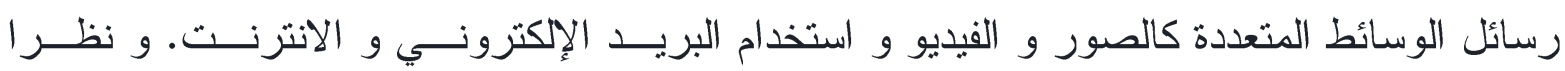

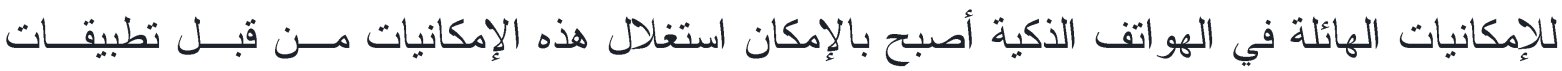

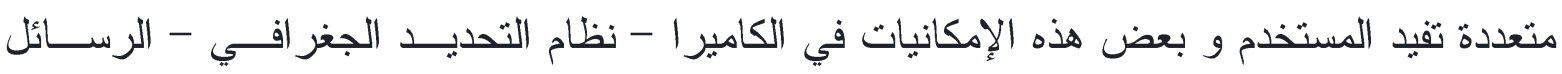

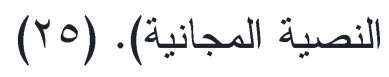

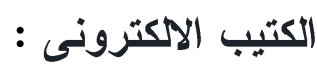

هو أحد أثُكال التعليم و التثريس الاككتروني، يتم من خلاله تحويل الكتب من صورتها الورقيـــة

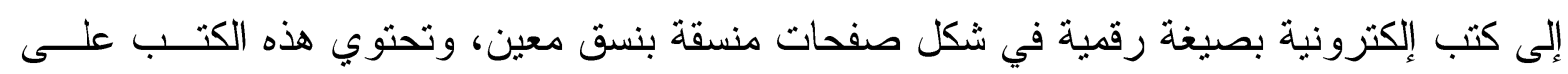


العديد من المثير ات السمعية و البصرية، لبعرض من خلال شبكة الانترنت أو من خلا أي وسـيط

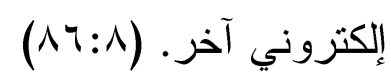

\section{جهاز عرض البيانات (data show):}

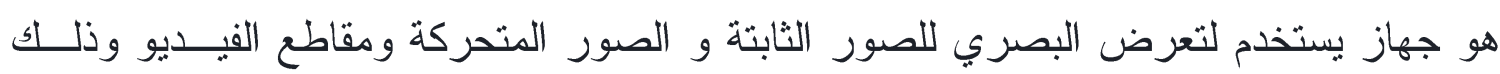

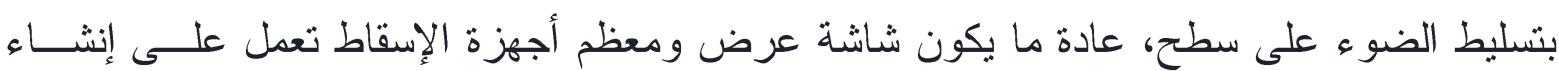
الصورة من خلال عبور ضوء ساطع عبر عدسات شفافة صغيرة لمساعدة المعلم على عرض مادته

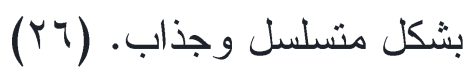

\section{:Face book}

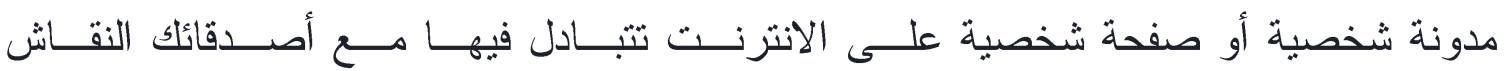

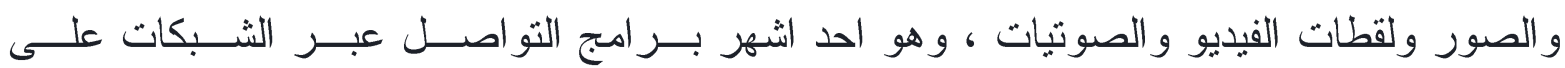
الانترنت.(·) المجموعة السرية في القيس بوك:

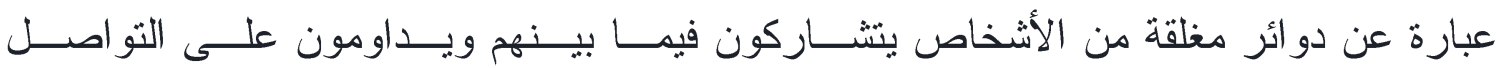
على فيس بوك. (YT)

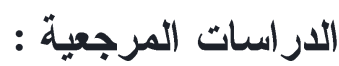

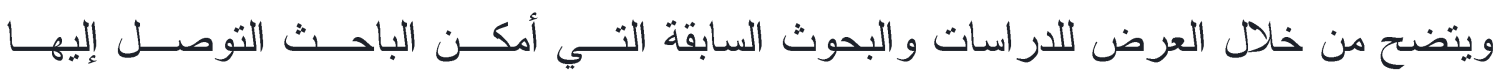

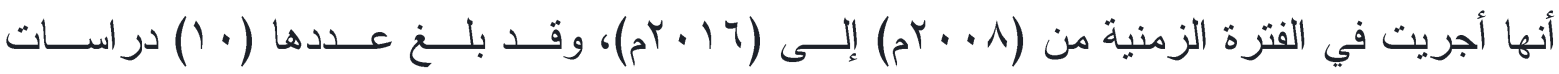
(^) در اسات عربية، (Y) در اسة إنجليزية

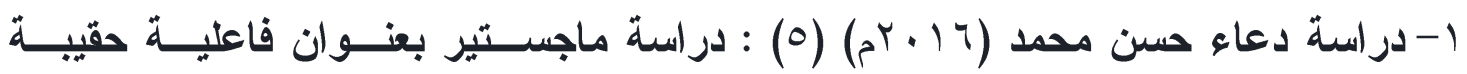
إلكترونية مدمجة قائمة على تطبيقات الويب الاجتماعية لتنمية مهارات توظيف مصــادر

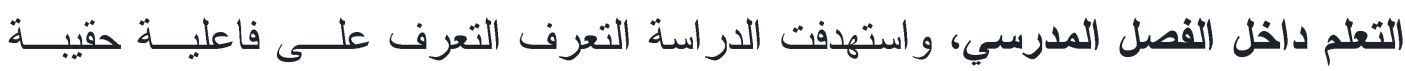

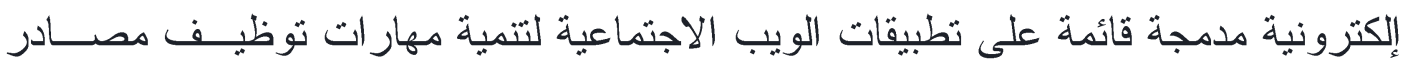

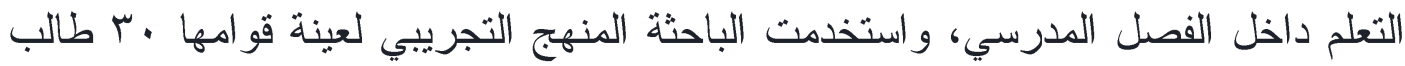

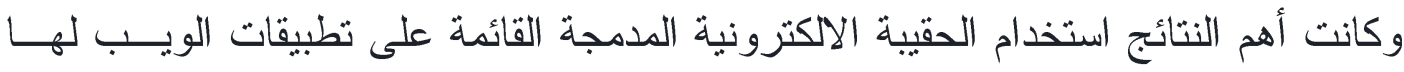
تأثثر إيجابي على تحسين مهار ات توظيف مصادر التعلم داخل الفصل المدرسي . 
r- دراسة فريد محمد السيد (10 • r م) (9) : ماجستير دراسة بعنوان تصميم فصل إلكتروني

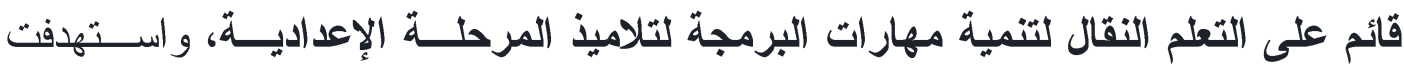

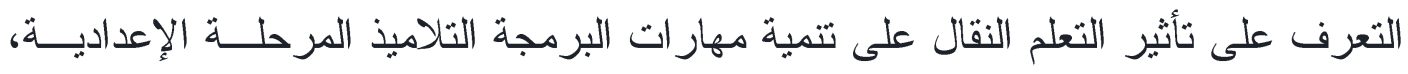

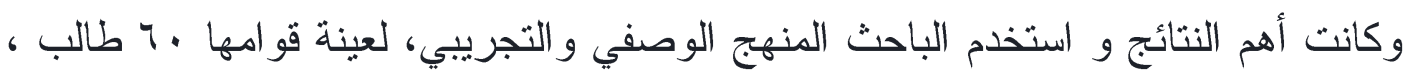

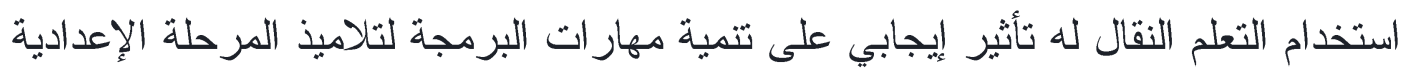

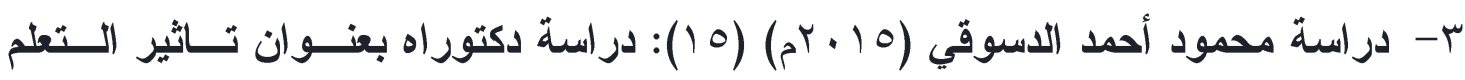

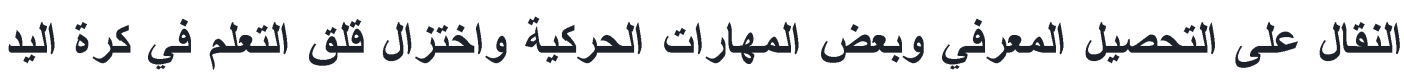

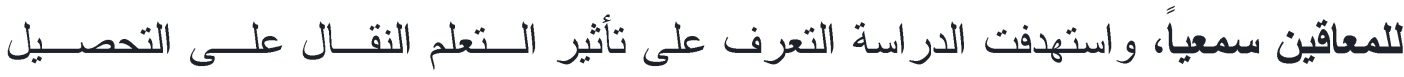

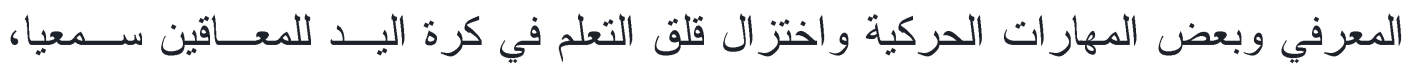

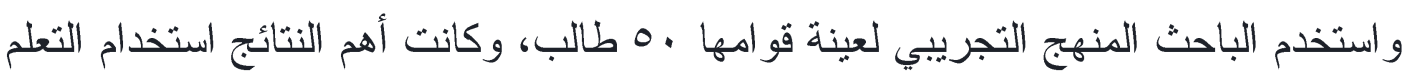

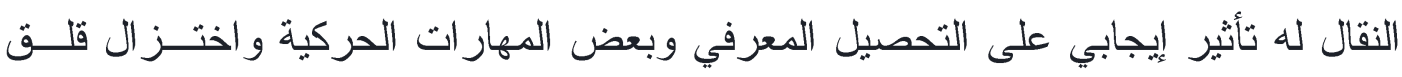
التعلم في كرة اليد للمعاقين سمعياً.

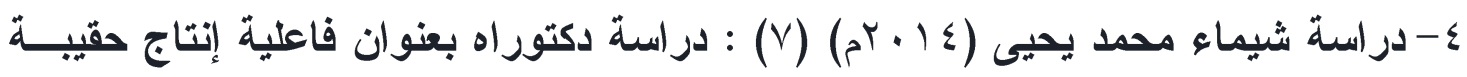

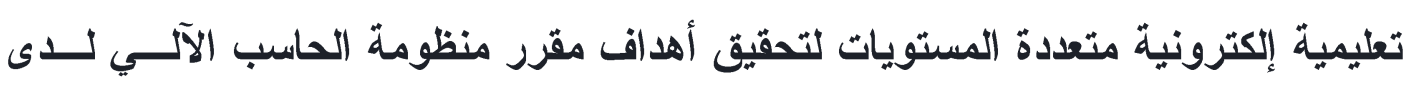

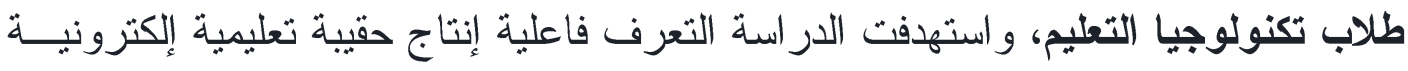

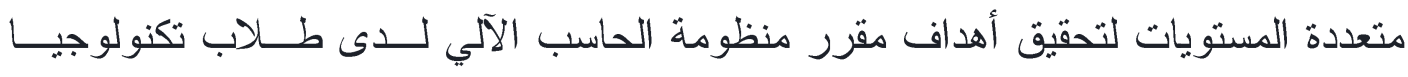

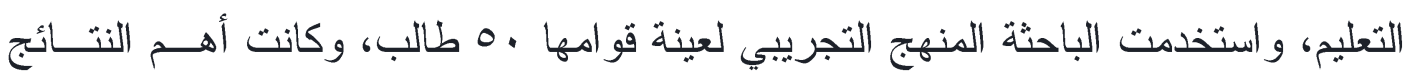

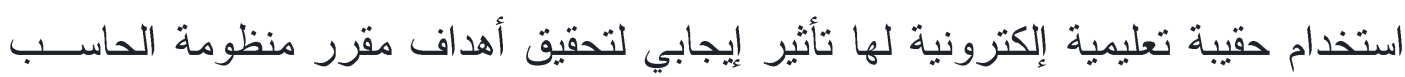

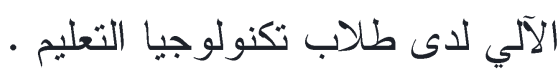

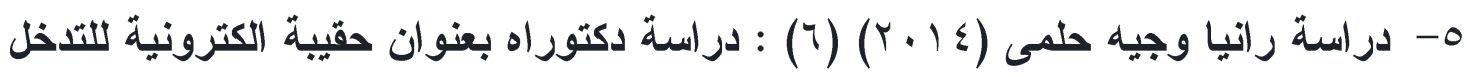

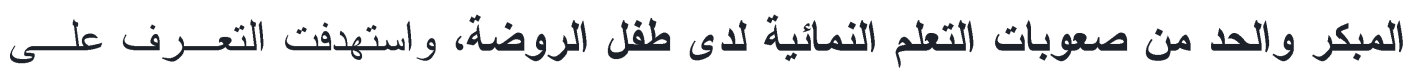

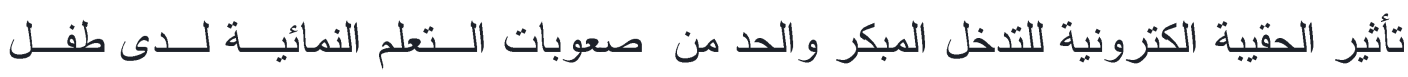

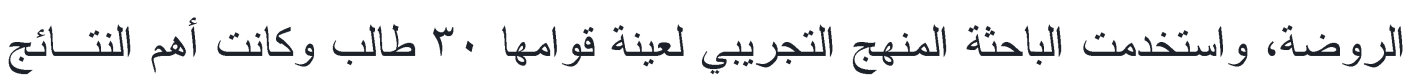

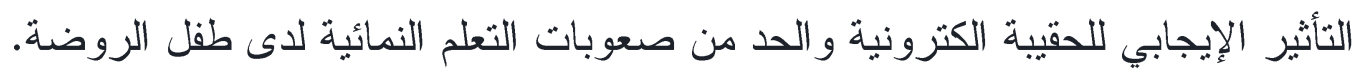

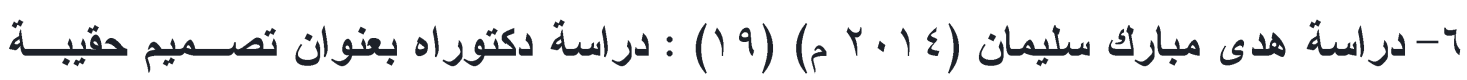

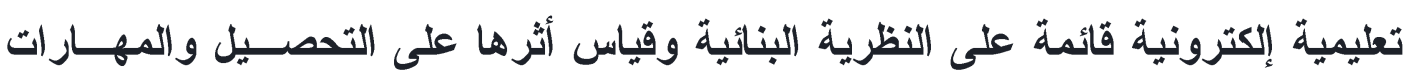

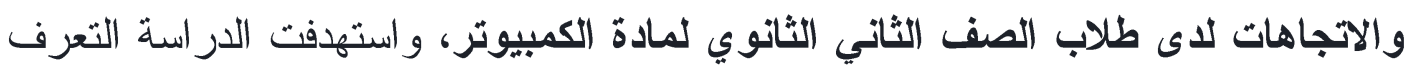

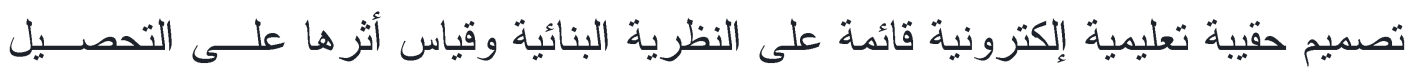

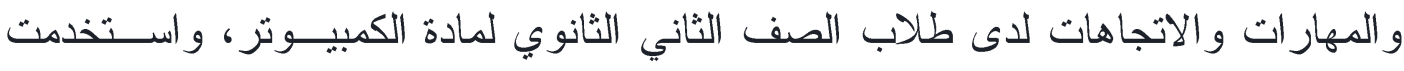
الباحثة المنهج التجريبي العينة قو امها م؛ طالبة ، وكانت أهم النتائج استخدام حقيبة تعليمية لكادية 
إلكترونية قائمة على النظرية البنائية لها تأثير إيجابي على تتمية المهار ات والاتجاهات لدى طلاب الصف الثاني الثانوي لمادة الكمبيوتز .

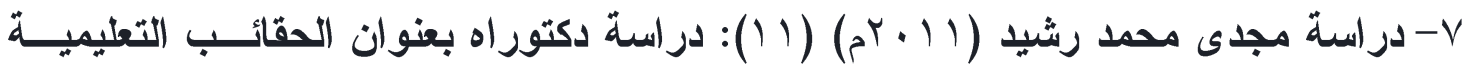
الإكترونية وأثرها على تحصيل طلاب جامعة القدس المفتوحـة واتجاهــــهم نحوهــا، و استهدفت الدراسة التعرف على تأثثر الحقائب التعليمية الإكترونية و أثرها على تحصــيل طلاب جامعة القدس المفتوحة واتجاهاتهم نحوها، واستخدم الباحث المنهج التجريبي لعينــة قو امها · 7 طالب، وكانت أهم النتائج التأثير الإيجابي للبرنامج باستخدام الحقائب التعليمية الإلكترونية و أثز ها الإيجابي على تحصيل طلاب جامعة القدس.

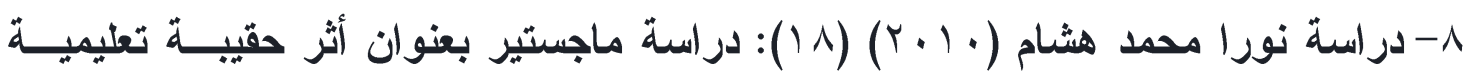
مبرمجة مقترحة على تعلم بعض المهارات الأساسية في الكار اتيه للمبتدئين، و اســتهدفت الدر اسة التعرف أثز حقبية تعليمية مبرمجة مقترحة على تعلم بعض المهار ات الأساسية في

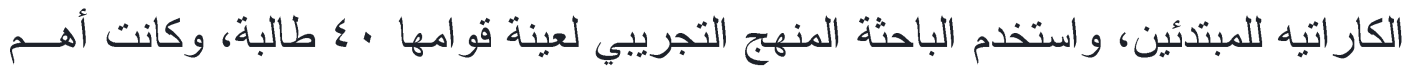
النتائج استخدام الحقيبة التعليمية المبرمجة لها تأثثر إيجابي على تعلـــم بعــ المهــار ات الأساسية في الكار اتيه للمبتدئين.

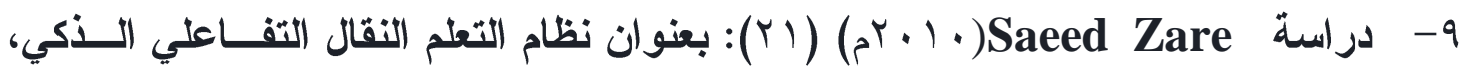
و استهدفت الدر اسة تهدف الدراسة للتعرف نظام التعلم النقال التهــاعلي الــذكي وتــأثيره الإيجابي على العملية التعليمية، و استخدم الباحث المنهج التجريبي، لعينة قو امها ع ب طالب، وكانت أهم النتائج استخدام نظام التعلم النقال التفاعلي الذكي لله تأثير إيجابي على العمليــة التعليمية.

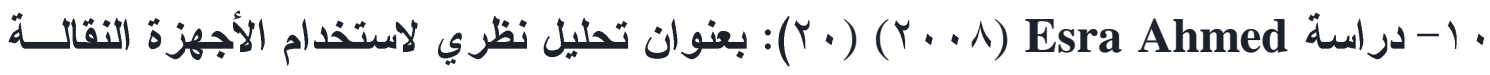
في التعليم العالي، واستهدفت الدراسة تهدف الدراسة لمعرفة أثز الإيجابي للتحليل نظـــري لاستخدام الأجهزة النقالة في التعليم العالي، واستخدمت الباحثة المنهج التجريبي لعينة قو امها 9 طالب، وكانت أهم النتائج التأثير الإيجابي للأجهزة النقالة على العملية التعليميــة فــي

$$
\begin{aligned}
& \text { التعليم العالي. } \\
& \text { إجراعات البحث: } \\
& \text { منهج البحث }
\end{aligned}
$$

استخدم الباحث المنهج التجريبي لمناسبته لطبيعـة هــذا البحــث مــن خــلال التصــميم التجريبي الذي يعتمد علـى القباســين القبلـي و البعــدي لمجمــوعتين ، إحــداهما ضـــابطة و 
مجتمع وعينة البحث:

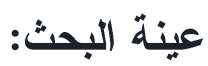

اشتملت العينة الكلية على عب برعم (سباح) وعينة البحث الاساسية على \& اسباح تم

إختيار هم بالطريقة العشو ائية من العينة الكلية ويمثلون نسبة ؟ ., إ من مجتمع البحث وقد تم تقسيم العينة الاساسية عشوائياً الى مجموعتين منساويتين وقوام كل منهما (r إسباح) إحداهما ضابطة و الاخرى تجريبية وتم إختيار • (1 سباحين من العينة الكلية لاجر اء الدراسة الاستطلاعية وتم استبعاد سباحين وذلك لعدم الانتظام فى التدريب .

جدول (1)

التوصيف الإحصائى لمجتمع وعينة البحث

\begin{tabular}{|c|c|c|c|c|}
\hline \multirow{2}{*}{ المستبعدون } & \multicolumn{3}{|c|}{ العينة الكلية } & \multirow{2}{*}{ مجتمع البحث } \\
\hline & الاستطلاعية & ضابطة & تجريبية & \\
\hline v & 1. & Ir & ir & \& \\
\hline
\end{tabular}

تم اختيار عينة البحث للأسباب التالية :

ا - قيام الباحث بتعليم وتدريب السباحة بنادى الصفوة الرياضى.

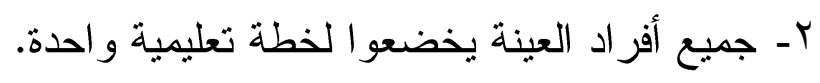

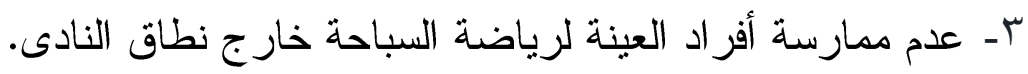

جدول (r) (ج)

تجانس عينة البحث الكلية فى المتغيرات المختارة (قيد البحث)

$(r \varepsilon=\dot{0})$

\begin{tabular}{|c|c|c|c|c|c|c|}
\hline الالتو اء & التقلطح & الوسيط & الآحر اف المعيارى & الحستوسط & وحدة القياس & المتغير ات \\
\hline$\cdot, r r$ & $\cdot, \Upsilon \wedge-$ & $9, \varepsilon$. & •, Yo & $9, r 9$ & سنة & السن \\
\hline., $1 r$ & $\cdot, V r-$ & Irq, . & $\varepsilon, r q$ & $1 r q, \varepsilon r$ & السنتيمتز & الطول \\
\hline$\cdot$, , 0 & $\cdot, 7 \cdot-$ & $r \cdot, \ldots$ & r,Or & $r \cdot, \wedge r$ & الكيلو جرام & الوزن \\
\hline
\end{tabular}




\begin{tabular}{|c|c|c|c|c|c|c|}
\hline $1,\{\Lambda$ & $\cdot, \wedge 9$ & $r, \ldots$ & •, Y & $r, I V$ & سنة & عدد سنوت الممارسة \\
\hline$\cdot, \cdot \varepsilon r-$ & $1, .9-$ & $q r, \ldots$ & $\varepsilon, 79$ & $71,0 \leq$ & السنتيمتر & طول الذراع \\
\hline$\cdot, 9 r-$ & ז & r०, 0. & $r, \ldots$ & $r_{0, \ldots}$ & السنتيمتر & طول العضد \\
\hline . ro- & $\cdot, \Delta \wedge-$ & $r r, \ldots$ & $r, \cdot r$ & rr,Ir & السنتيمتر & طول الساعد \\
\hline$\cdot, 90-$ & •,Ar & $10, \ldots$ & $1,0 \mathrm{~V}$ & $1 \varepsilon, 99$ & السنتيمتر & طول الكف \\
\hline$\cdot, \cdot 7-$ & $1,0 r$ & $\vee 9,0$. & $\varepsilon, \varepsilon \mu$ & $\mathrm{Vq,Yq}$ & السنتيمتر & طول الرجل \\
\hline $1,0 \leqslant-$ & $0,7 \varepsilon$ & $\varepsilon 1, \ldots$ & $r, \wedge \varepsilon$ & $\varepsilon \cdot, \vee q$ & السنتيمتر & طول الفخذ \\
\hline$\cdot, r q$ & $\cdot, \leqslant r$ & r^,.. & $r, O \leqslant$ & $r \wedge, v i$ & السنتيمتر & طول الساق \\
\hline$\cdot, 70-$ & $\cdot, \varepsilon \vee-$ & ri,o. & $1, \wedge r$ & $r \cdot, v_{0}$ & السنتيمتر & طول القدم \\
\hline $1,7 \wedge-$ & r, r & r^,०. & $\varepsilon, \wedge$ & rv,ro & السنتيمنر & طول الجذع \\
\hline
\end{tabular}

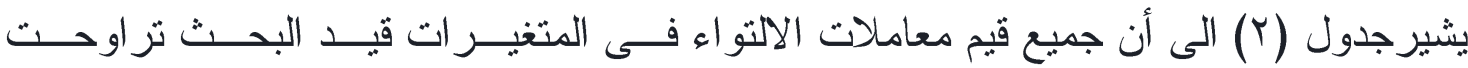

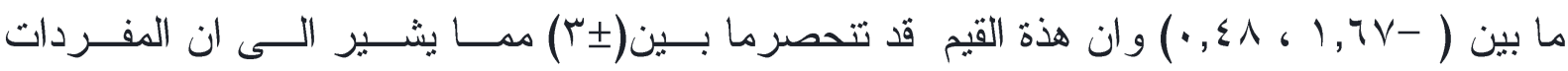
تتوزع توزيعا اعتداليا مما يشير الى تجانس العينة.

تكافؤ عينة البحث:

جلول (r)

تكافؤ عينة البحث فى بعض المتغيرات البدنية و المهارية المختارة

$(r \varepsilon=\dot{0})$

\begin{tabular}{|c|c|c|c|c|c|c|c|}
\hline \multirow[b]{2}{*}{ قيمة (ت) } & \multicolumn{2}{|c|}{ المجموعة التجريبية } & \multicolumn{2}{|c|}{ المجموعة الضابطة } & \multirow[b]{2}{*}{ وحة } & \multirow{2}{*}{\multicolumn{2}{|c|}{ المتغيرات }} \\
\hline & الالمعراف & الحسابى & الاحعراف & الحسابى & & & \\
\hline - , 94 & $r, .1$ & $r \ldots, r r$ & r,A & $r_{\cdots, r_{0}}$ & بالسنتيمتر & (قوة عضلية للأراعين) & \\
\hline$\cdot, v$. & $1,9 \varepsilon$ & $\checkmark, v$. & 1,01 & T, & بالسنتيمتر & مرونة الجذع (أماماً) & E. \\
\hline • & $1, \varepsilon r$ & $0 ., \varepsilon$. & 1, ro & $\varepsilon q, v \vee$ & بالسنتيمتر & مرونة الكتفين (خلفاً) & $\frac{5}{6 .}$ \\
\hline •,9 & $1, . r$ & $r 1,1 r$ & $1, .9$ & 41,19 & بالثانية & الرشاقة & \\
\hline., 19 & $1, \cdot r$ & 19,19 & $\cdot, v r$ & 19,71 & بالثانية & التو افق & \\
\hline$\cdot, \mathrm{vi}$ & I,Ar & ए৭,४ & $1,0$. & rq,q) & بالدرجة & مستوى الاداء لسباحة هr مل الصدر & 点 \\
\hline
\end{tabular}


يتضح من جدول (r) ان جميع قيم (ت) المحسوبة فى المتغير ات قيد البحث بين المجموعتين التجريبية و الضابطة قد تراوحت ما بين (با9, ، 99 1, •) وهى أقل من قيمة (ت) الجدولية عند مستوى

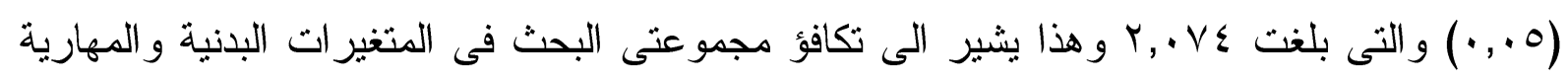
قيد البحث.

\section{وسائل جمع البيانات}

أدوات البحث

$$
\text { r - البيانات الخاصة بالمتعلمين ( الاسم - السن - الطول - الوزن ) }
$$

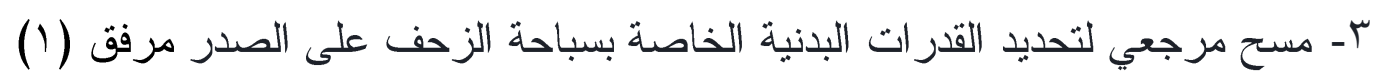

الاختبارات

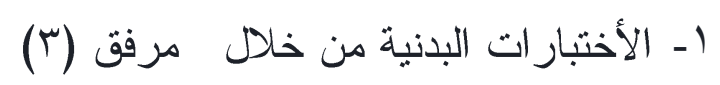

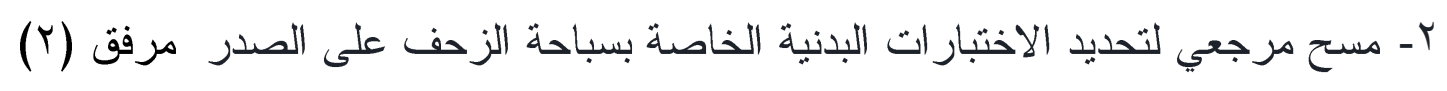

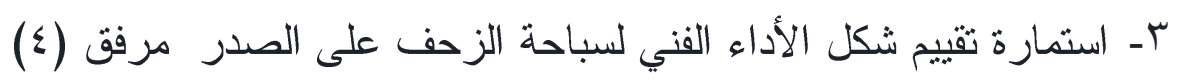

الأدوات والأجهزة المستخدمة في البحث :

مata Show قاعة دراسية مجهزة بالكمبيوتر وجهاز

جهاز الهاتف المحمول

ميز ان طبي

جهاز الديناموميتر

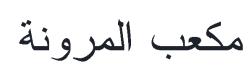

كرات طبية

محتوى البرنامج: مرفق (•)

تعتبر عملية تحديد محتوي البرنامج من العمليات الصــعبة و التــي تمثـل أهميــة كبيــرة جــــا،

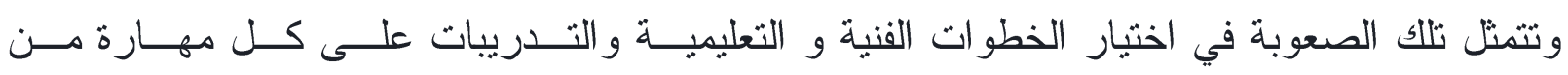

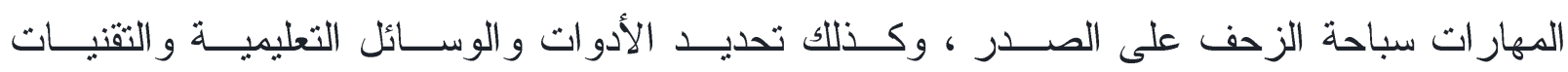




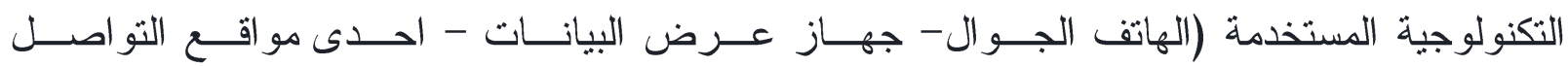

$$
\text { الاجنماعي). }
$$

الار اسة الاستطلاعية

قام الباحث بإجر اء الدر اســـة الإســنطلاعية بهــدف حســاب المعـاملات العلميــة للاختبــارات المستخدمة في البحث.

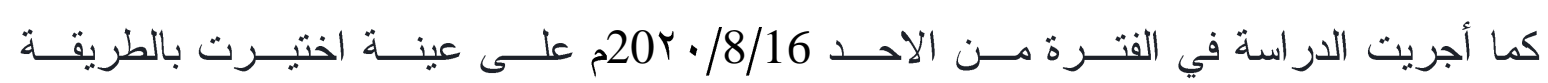
العشو ائية من مو اليد 2012 م وخارج عينة البحث الأساسية وقو امها ( • () سباحين .

وذللك للتاكد و التعرف على كافة النواحي الإدارية و الفنية التنظيمية الخاصة بتنفيذ البحث : 1- معرفة مدى ملائمة زمن الوحدة التعليمية (.ب دقيقة) لأجز اء الوحدة التعليمية. r- معرفة ملائمة زمن مشاهدة التطبيق البرمجية - الجروب التعليمي. r- مدى مناسبة المكان لإجر اء تطبيق محتوي البرنامج التعليمي . عـ أختبار الأدوات و الأجهزة المستخدمة في البحث ومدى ملائمنها مع عدد العينة . 0ـ الوقوف على مدى مناسبة محتوى البرنامج التعليمى لعينة البحث. 7- التأكد من سهولة الأختبار ات.

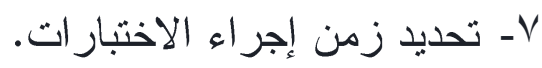
^- التأكد من المعاملات العلمية للاختبار ( الثبات - الصدق ) معاملات الصدق للاختبارات البذنية و المهارية قيد البحث:

تم حساب معامل صدق الأختبارات (صدق التمايز) من خلال تطبيق الاختبار على (r. سباح) مقسمون إلى مجموعتين مجموعة مميزة (·ل سباحين) من سباحى نادى بتروسبورت من مو اليد 2008م و مجموعة غير مميزة (• ( سباحين) وهم عينة الدراسة الاستطلاعية كما هو موضح

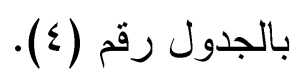


جلول (ع)

دلالة الفروق بين متوسطات قياسات المجموعتين المميزة وغير المميزة فى المتفيرات البدنية والمهارية قيد البحث

$(r \cdot=r+10)$

\begin{tabular}{|c|c|c|c|c|c|c|c|}
\hline \multirow{3}{*}{ قالمحسة (ت) } & \multicolumn{2}{|c|}{ المجموعة المميزة } & \multicolumn{2}{|c|}{ المجموعة غير المميزة } & \multirow{3}{*}{ وحدة } & \multirow{3}{*}{\multicolumn{2}{|c|}{ المتغير ات }} \\
\hline & الانحر اف & المتوسط & الاتحر اف & المتوسط & & & \\
\hline & المعيارى & الحسابى & المعيارى & الحسابى & & & \\
\hline$* \varepsilon, \leqslant 0$ & $1, \varepsilon \wedge$ & rYq,Y. & $\varepsilon, r q$ & $197, Y$. & بالسنتيمتر & (قوة عضلية للذر اعين) & \\
\hline$* \varepsilon, r \wedge$ & $\cdot, .9$ & $11,0 r$ & $1, \cdot v$ & $\uparrow, \wedge$. & بالسنتيمتر & مرونة الجذع (أماماً) & $\underline{E}$ \\
\hline$* \wedge, 7 \vee$ & l,Ar & $\diamond \wedge, \ldots$ & $\cdot, 9 \varepsilon$ & $\varepsilon q, r$. & بالسنتيمتر & مرونة الكتفين (خلفاً) & \\
\hline$* \vee, Y q$ & $\cdot, 1 \leqslant$ & $1 \wedge, \cdot \wedge$ & $1, \cdot r$ & $r \cdot, \varepsilon \wedge$ & بالثانية & 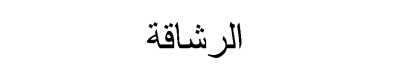 & \\
\hline$* \vee, \varepsilon \wedge$ & . Ir & $|\wedge, r|$ & .911 & $r \cdot, r \varepsilon$ & بالثانية & 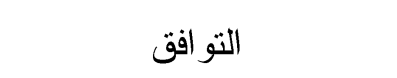 & \\
\hline$* q, \leqslant 0$ & $1, r v$ & $r \varepsilon, 0$. & $1, \vee \wedge$ & ५^, & بالارجة & مستوى الاداء لسباحة هبم على الصدر & E \\
\hline
\end{tabular}

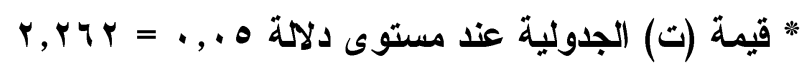

يتضح من الجدول السابق أن هناك فروق دالة إحصائيا بين المجموعتين المميزة وغير المميزة

فى اختبار ات القدرات البدنية الخاصة لصالح المجموعة المميزة ، حيث أن جميع قيم (ت) المحسوبة أكبر من قيمتها الجدولية عند مستوى دلالة ه.., ، ، مما يشير إلى صدق هذه الأختبار ات فى قياس ما وضعت من أجله.

معاملات الثبات للاختبارات البذنية والمهارية قيد البحث:

test - تم حساب الثبات الخاص بالاختبارات عن طريق تطبيق الاختبار و إعادة نطبيقه

retest

تجرى فى نفس التوقيت و بنفس الثروط فى القياسين ، كما هو موضح بالجدول رقم (0). 
جدول (0)

معامل الثبات بين التطبيق الأول والتطبيق الثانى للإختبارات البذنية والمهارية قيد البحث

$(1 \cdot=\dot{0})$

\begin{tabular}{|c|c|c|c|c|c|c|c|}
\hline \multirow{2}{*}{ معامل } & \multicolumn{2}{|c|}{ التطبيق الثانى } & \multicolumn{2}{|c|}{ التطبيق الأول } & \multirow{2}{*}{ القياس } & \multirow[t]{2}{*}{ المتغيرات } & \\
\hline & الاتحرا & الحسابى المتوسط & الالحرا & الحسابى المسط & & & \\
\hline$* . .9 r$ & $r, q \mu$ & $\begin{array}{c}194,9 \\
.\end{array}$ & $\varepsilon, r q$ & $\begin{array}{c}194, r \\
.\end{array}$ & بالسنتيمتر & (قوة عضلية للازراعين) & \\
\hline$*, q \vee$ & $1, \cdot 1$ & 7,94 & $1, \cdot v$ & $\uparrow, \wedge$. & بالسنتيمتر & مرونة الجذع (أماماً) & $E$ \\
\hline$*, 9 \varepsilon$ & $\cdot, \wedge \varepsilon$ & $\varepsilon q, \varepsilon$. &., 90 & $\leq q, r$. & بالسنتيمتر & مرونة الكتفين (خلفاً) & tis. \\
\hline$*, 91$ & $\cdot, 9 \vee$ & $r_{\cdot, q}$, & $1, .1$ & $r_{\bullet},\{\wedge$ & بالثانية & الرشاقة & \\
\hline$*, 94$ & $\cdot, 91$ & $r \cdot, \varepsilon q$ & $\cdot, 91$ & $r \cdot, r r$ & بالثانية & التو افق & \\
\hline$*, 91$ & $r, \cdot \varepsilon$ & $r \wedge, \Lambda$. & $1, \vee \wedge$ & ২^,ף. & بالارجة & مستوى الاداء لسباحة & $\underline{\underline{E}}$ \\
\hline
\end{tabular}

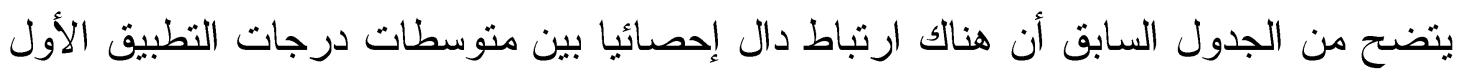

و الثانى فى الأختبار ات البننية و المهارية ، حيث إن جميع قيم (ر) المحسوبة أكبر من قيمتها (ر) الجدولية عند مستوى دلالة ه., • مما يشير إلى ثبات الأختبار ات.

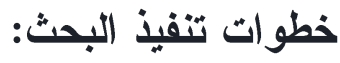

بعد تحديد المتغيرات الاساسية والادوات المستخدمة قام الباحث باجر اء الاتى :

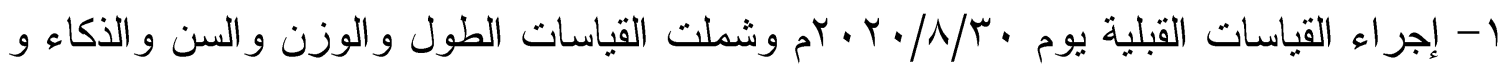

طول الذراع وطول الكف وطول الرجل وطول القدم وطول الجذع لكل سباح ، وتم قبل إجر اء الاختبار جلسة لثرح مفهوم الاختبار و الهدف منه. 


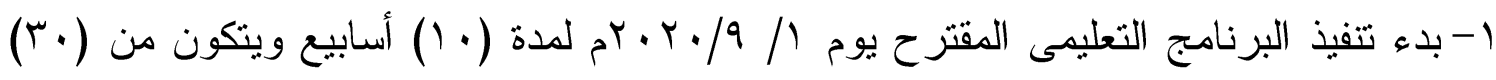

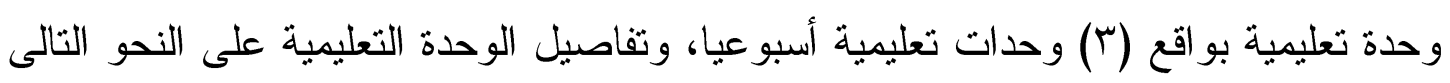
:- (· دقائق مشاهدة البرمجية قبل بداية الوحدة من خلال بدائل الحقيبة التعليمية الاككترونية - r دقيقة اعمال ادارية - ه دقائق احماء - ه 1 دقيقة اعداد بلنى - ه بدقيقة

$$
\text { تطبيق المهارة - r دقائق ختام ) }
$$

r-تم إجراء القياسات البعدية يوم r// / / /.r.rم وبنفس التسلسل السابق ومقارنتة بالقياس

القبلى باستخدام الأساليب الاحصائية اللازمة.

المعالجات الإحصائية المستخدمة:

سوف يستخدم الباحث الأسلوب الإحصائي المناسب للبحث ويقترح في ضوء ما توصل إلية من خلال الدر اسات و البحوث السابقة ما يلي: - الباتي

المتوسط الحسابي .

الإنحر اف المعياري.

النسبة المئوية.

معامل اختبار (T) لحساب دلالة الفروق .

نسبة التحسن •

الإلتلواء .

معامل ارتباط بيرسون. 


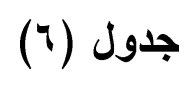

دلالة الفروق بين متوسطات درجات القياسات القبلية و البعدية للمجموعة الضابطة فى المتغيرات المهارية لسباحة الزحف على الصدر

$r=\dot{H}$

\begin{tabular}{|c|c|c|c|c|c|c|}
\hline \multirow{2}{*}{ قاتمة } & \multirow{2}{*}{ المتوسطين بين } & \multicolumn{2}{|c|}{ القياس البعدى } & \multicolumn{2}{|c|}{ القياس القبلى } & \multirow[b]{2}{*}{ المتغير ات } \\
\hline & & الانحر اف & المتوسط & الانحر اف & المتوسط & \\
\hline$* 19, r q$ & $\varepsilon, \varepsilon \diamond 9$ & $\cdot, \wedge 11$ & $\bullet, \vee 0$. & •,YYI & 1, Iq1 $^{\prime}$ & حركات الذراعين \\
\hline$* 17,7 r$ & $\varepsilon, 10 \wedge$ & $\cdot, \vee \leqslant \wedge$ & T &., 0 , 9 & r, IVo & ضربات الرجلين \\
\hline$* r \cdot, 17$ & סץז", \& & • & $0, \cdot \wedge r$ & • & $\cdot, \varepsilon \otimes \wedge$ & السباحة الكاملة \\
\hline$* \varepsilon r, v q$ & $|r, r \leq|$ & $1, .01$ & 18,174 & , & r,qro & المجموع الكلى \\
\hline
\end{tabular}

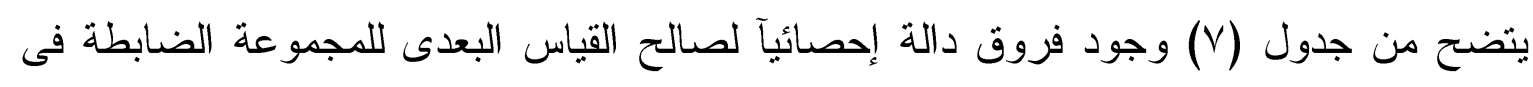
تعلم سباحة الزحف على الصدر حيث ان جميع قيم (ت) المحسوبة أكبر من قيمتها الجدولية عند مستوى دلالة 0.

ويرجع الباحث الفروق بين القياسين الى تاثير الحقيبة التعليمية الالكترونية على تعلم سباحة الزحف على الصدر للى سباحى المجموعة الضابطة نتيجة لتعلم المهارات وممارستها و التنريب عليها.

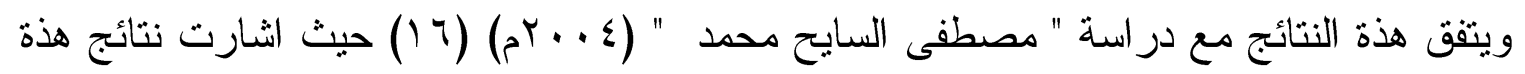
الدراسات الى ان الاسلوب التقليدى يتصف بان وجود المعلم لة أهمية وتعليماتة بناءة كما اثار ايضا

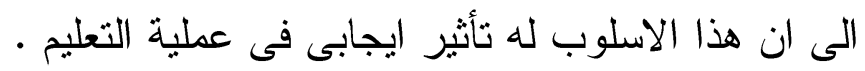


وبهذا يتحقق الفرض الاول للبحث و الذى ينص على انة توجد فروق دالة إحصائيا بين منوسطات القياسين القبلى و البعدى للمجموعة الضابطة فى تعلم سباحة الزحف على الصدر ولصالح القياس

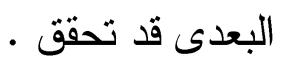

ثانيآ: عرض نتائج الفرض الثانى ومناقشتها. جدول (v)

دلالة الفروق بين متوسطات درجات القياسات القبلية و البعدية للمجموعة التجربية فى المتغيرات المهارية لسباحة الزحف على الصدر

$1 Y=\dot{U}$

\begin{tabular}{|c|c|c|c|c|c|c|}
\hline \multirow{2}{*}{$\begin{array}{c}\text { المحسوبة } \\
\text { اتة }\end{array}$} & \multirow{2}{*}{ المتوسط بين } & \multicolumn{2}{|c|}{ القياس البعدى } & \multicolumn{2}{|c|}{ القياس القبلى } & \multirow[b]{2}{*}{ المتغير ات } \\
\hline & & الانحر اف & المتوسط & الانحر اف & المتوسط & \\
\hline$* r r, v r$ & $7, . \times 0$ & .099 & $V, \varepsilon 17$ & $\cdot, r \leq r$ & $1, r \leqslant 1$ & حركات الذراعين \\
\hline$* \mid \wedge, 0$ & $0, \leqslant 0$ & •, VYo & $v, v \cdot \wedge$ &., 00. & $r, Y \diamond \wedge$ & ضربات الرجلين \\
\hline$* r q, \vee \varepsilon$ & $T, r \otimes \Lambda$ & $\cdot, \varepsilon 0$. & $\neg, v \cdot \wedge$ & rדז, , & $\cdot, \varepsilon \odot$ & السباحة الكاملة \\
\hline$* r \wedge, \vee r$ & IV,VAr & $1,0 \times 1$ & r I,Arr & •, VYr & $\varepsilon, \infty$ & المجموع الكلى \\
\hline
\end{tabular}

يتضح من جدول (آ) وجود فروق دالة إحصائياً لصالح القياس البعدى للمجموعة التجريبية فى مستوى الأداء المهارى لسباحة الزحف على الصدر حيث ان جميع قيم (ت) المحسوبة أكبر من قيمتها الجدولية عند مستوى دلالة 0 ., - .

ويرجع الباحث الفروق بين القياسين الى تاثير الحقيبة التعليمية الالكترونية على تعلم سباحة الزحف على الصدر لدى سباحى المجموعة التجريبية

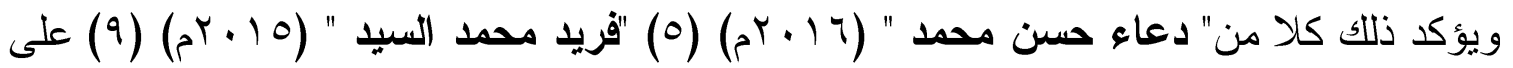
أهمية الحقيبة التعليمية الاكترونية والتاثير الايجابى لتطبيقات الموبايل على تتمية مهارات الكتيب وتحسين مهارات توظيف مصادر التعلم داخل عملية التعليم . 
وبهذا ينحقق الفرض الثانى الذى ينص على انة نوجد فروق دالة إحصائيا بين متوسطات درجات القياسين القبلى و البعدى للهجموعة التجريبية فى تعليم سباحة الزحف على الصدر ولصالح القياس

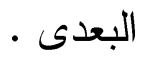

ثالثا: عرض نتائج الفرض الثالث ومناقشتها.

$$
\text { جدول (^) }
$$

دلالة الفروق بين متوسطات درجات القياسات البعدية للمجموعتين التجريبية والضابطة فى

$$
\text { المتغيرات المهارات قيل البحث }
$$

\begin{tabular}{|c|c|c|c|c|c|c|}
\hline \multirow{2}{*}{ المحسوبة } & \multirow{2}{*}{ المترق بين } & \multicolumn{2}{|c|}{ القياس البعدى } & \multicolumn{2}{|c|}{ القياس القبلى } & \multirow[b]{2}{*}{ المتغير ات } \\
\hline & & الأحر اف & المتوسط & الآحر اف & المتوسط & \\
\hline$* \bullet, V r$ & 1,74 & $\cdot, \wedge 11$ & $\bullet, v_{0}$. &., 099 & $V, \varepsilon 17$ & مركات الذراعين \\
\hline$* \varepsilon, \varepsilon \wedge$ & $1, r v o$ & $\cdot, \vee \leqslant \wedge$ & Trr & $\cdot, v \circ r$ & $v, v \cdot \wedge$ & ضربات الرجلين \\
\hline$* 9,91$ & סזד ו, & . & $0, \cdot \wedge r$ & $\cdot, \leqslant 0$. & $\neg, v \cdot \wedge$ & السباحة الكاملة \\
\hline$* \wedge, 0 \varepsilon$ & $\varepsilon, 74 V$ & $1, .01$ & 18,174 & $1,0 \vee 1$ & r & المجموع الكلى \\
\hline
\end{tabular}

يتضح من جدول (^) وجود فروق دالة إحصائياً لصالح القياس البعدى للمجموعة التجريبية فى هى تعلم سباحة الزحف على الصدر حيث ان جميع قيم (ت) المحسوبة أكبر من قيمتها الجدولية عند

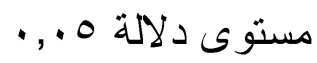

ويرجع الباحث الفروق بين القياسين الى تاثير الحقية التعليمية الالكترونية على تعلم سباحة الزحف على الصدر لاى سباحى المجمو عة التجريبية. ويعزو الباحث تقدم سباحى المجموعة التجريبية على المجموعة الضابطة فى القياسات البعدية لمتغيرات البحث المهارية نتيجة للتنريس بالبرنامج التعليمى باستخدام الحقيبة التعليمية الالكترونية للمجموعة التجريبية دون الضابطة ، حيث ساعد على سرعة توصيل المادة العلمية للسباح وتوفير عامل الاثارة و التشويق اثناء عملية التعليم بصورة افضل. 
ويتفق ذلك مع ما أثنارة الية " عادل السيد سرايا " (V...rم) (^) الحقيبة التعليمية الالكترونية نظام تعليمى متكامل مصمم بطريقة منهجية تساعد الطلاب على التعلم ، وتتثمل مجموعه من المو اد التعليمية المترابطة ذات الاهداف المتعددة بحيث يتفاعل معها الطالب وذلك باشر اف المعلم ويشير "جمال على الدهثان ، مجدى محمد يونس " (1. ․ rم) (ع) ان التعليم النقال شكل من اشكال التعلم الالكترونى ولكنة يعتمد على اللاسلكية مثل الهواتف النقالة ،و الهو اتف الذكية حيث انها يهيئ فرصا عديدة لاحداث التفاعل واجر اء التعليم التعاونى بين الطلاب ووبعضهم وبين الطلاب و المعلم والذى لاتحققة بعض الطرق الاخرى بهذة الكفاءة العالية . ومما سبق نجد أن الفرض الثالث للبحث و الذى ينص على أنة نوجد فروق دالة إحصائيا بين

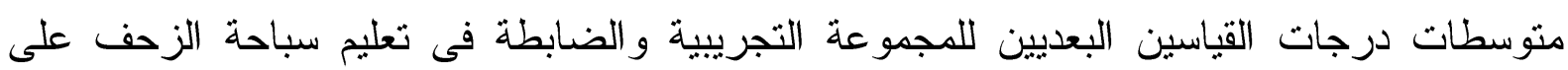
الصدر ولصالح القياس البعدى للمجموعة التجريبية قد تحقق.

الاستخلاصات و التوصيات :

أولا: استخلاصات: - أو

هؤثر البرنامج التعليمى باستخدام الحقيبة التعليمية الالكترونية بشـــل إيجـابى علــى تعلــم سباحة الزحف على الصدر للبر اعم.

أن تطبيق برنامج التعليمى باستخدام الحقيبة التعليمية الآكترونية لـــة تــاثير ايجابيــا علـى رفع مستوى الاداء لتعلم سباحة الزحف على الصدر.

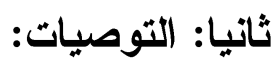

ضرورة استخدام الوحدات التعليميــة ( باســتخدام الحقيبـة التعليميــة الالكترونيــة) فــى تعليم المهار ات الاساسية الخاصة بسباحة الزحف على الصدر و العينات المماثلة لها. تطويع الحقيبة التعليمية الاككترونية لتعليم وتحسين الاداء المهارى فى السباحة. 
1- أحمد محمد سالم : - تكنولوجيا التعلــيم و التعلــيم الإلكترونــي، الريــاض، مكتبــة الرشـــ، $\cdot\left(r^{\prime} \cdot r\right)$

ץ- أحمد محمد سالم : - التعلم الجو ال رؤية جديـدة للــتعلم باســتخدام التقنـــات اللاســلكية ، المؤتمر العلمي الثامن عشر للجمعيــة المصــرية بالمنـــهج وطــرق التـدريس، جامعــة عـين شمس، القاهرة ، ؟ج . بام .

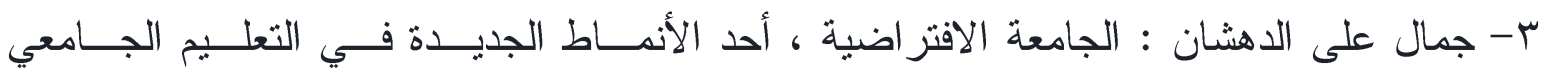
- مصر العربية للطباعة والنشر - القاهرة، (9 . ب (ب).

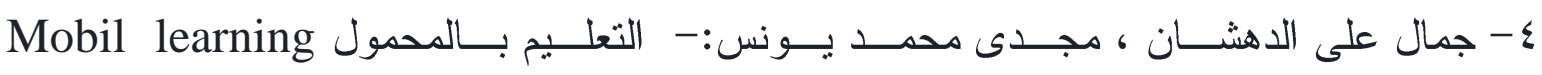

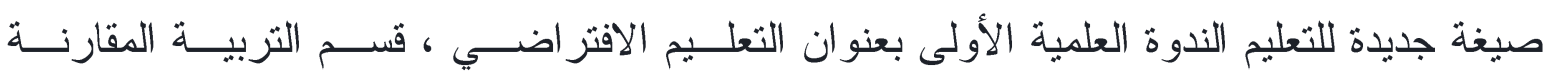
و الإدارة التعليمية، كلية التربية، جامعة كفر الثيخ، (1. . بم).

ه- دعاء حسن محمد : التعرف على فاعلية حقيبة إلكترونيــة مدمجــة قائمسـة علـى تطبيةــات الويب الاجتماعية لتتمية مهار ات توظيف مصادر الــتعلم داخــل الفصـل المدرسـي ، ماجســتير ، كلية التربية جامعه عين شمس، 17 ( ب م.

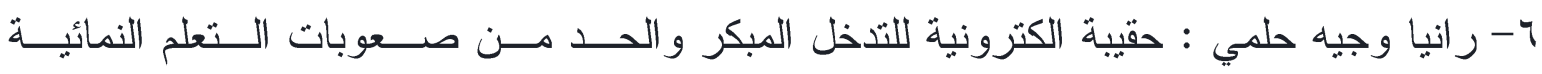
لدى طفل الروضة، رسالة دكتور اه ، كلية رياض الاطفال ، جامعة القاهرة ، عـ الب بم. V- شيماء محمد يحيى : فاعلية انتاج حقيبــة تعليميــة إلكترونيــة متعـددة المســتويات لتحقبـق

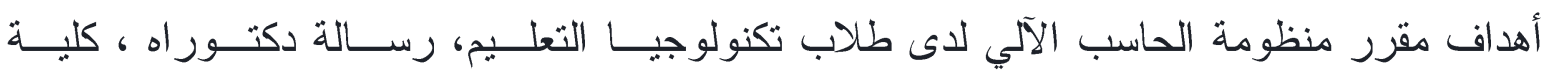
التربية النوعية، جامعه عين شمس، ع ا ـrم. 
^- عادل السيد سر ايا: تكنولوجيا التعليم ومصادر الـتـعلم، مفــاهيم نظريــة، تطبيقــات عمليــة،

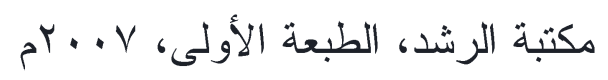

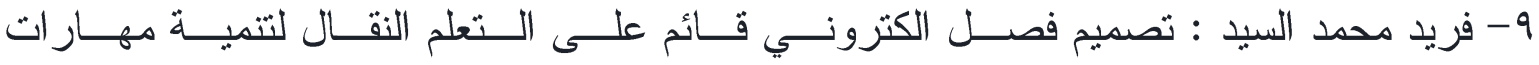
البرمجة لتلاميذ المرحلة الإعداديــة، رســالة ماجسـتير ، كليــة التربيــة، جامعـــة المنصــورة، $\cdot r^{r} \cdot 10$

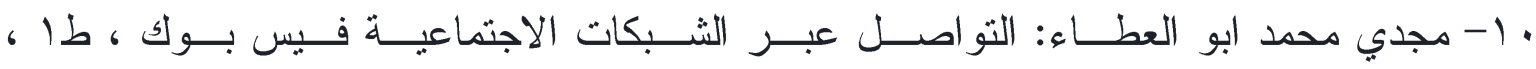

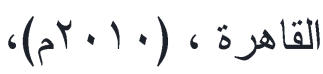

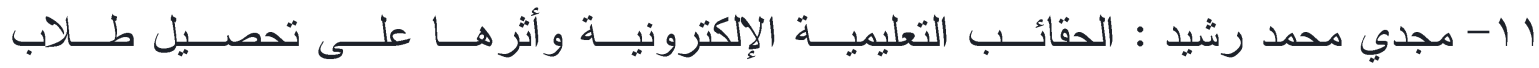

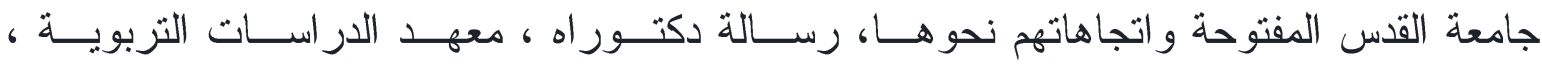

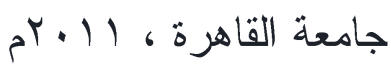

ب ا - محمد سعد زغلول ، مكارم حلمى أبــو هرجــه، هــائي ســعيد عبــــ المــنعم: تكنولوجيــا التعلم وأساليبها في التربية الرياضية، مركز الكتاب للنشر، القاهرة، ( +. بم.

برا- محمد محمد الحماحمي : التعليم النقــال مرحلــة جديــدة مــن التعلــيم الإلكترونــي مجلــة المعلوماتية التقانة في التعليم ، القاهرة العدد 9، شهر آبريل ج ؟ . بم.

ع ا- محمد محمود الحيلة : اثز الوسائط المتعددة المحوســبة و المعروضــة بواســة جهــاز (

(data show فى تحصيل طلبة الصف السابع في مــادة العلــوم ، المجلــة العربيــة للتربيــة ،

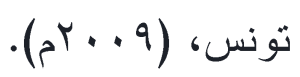

1 - محمود أحمد الدسوقي : تأثير التعلم النقال علــى التحصــيل المعرفـي وبعـض المهــار ات

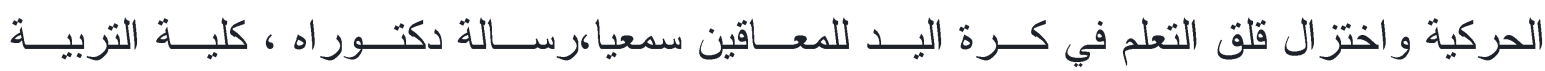
الرياضية، جامعة المنصورة 10 10 ب ام. 
71 ا- مصطفى السايح محمد : المنهج التكنولوجي وتكنولوجيا التعلــيم و المعلومــات فــي التربيـــة

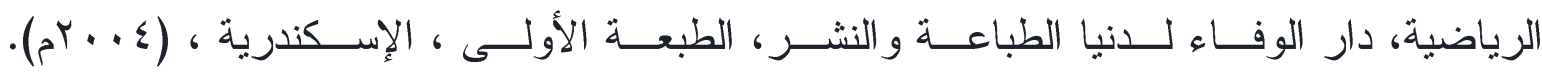
IV - نبيل جاد عزمي : بيئات التعلم التفاعلية، يسطرون للطباعة و النشر ، القاهرة ،(0 ( rم). 1ا- نور ا محمد هشام : أثر حقيبة تعليمية مبرمجــة مقترحسـة علـى تعلــم بعـض المهـار ات

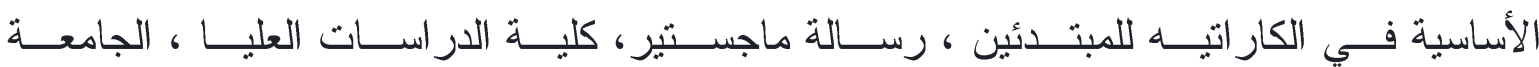

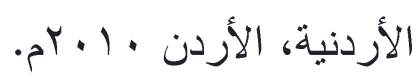

9 1- هدى مبارك سليمان: تصميم حقيـــة تعليميــة إلكترونيــة قائمسـة علــى النظريــة البنائيــة وقياس أثرها على التحصيل و المهــار ات و الاتجاهــات لــدى طــلاب الصــف الثـاني الثـانوي لمادة الكمبيوتز ، رسالة دكتور اه ، معهد الدراسات التربوية ، جامعة القاهرة، ـ ا ـ بم.

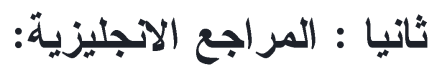

20-Esra Ahmed Wali: Reinterpreting Mobile Learning An Activity Theoretic Arialysis Of The Use Of PortableDevices In Higher Education, Submitted ForThe Degree of Doctor Of Philosophy,University Of London, November 2008.

21-Saeed Zare: Intelligent Mobile Learning Interaction System (IMIS), A Personalized Learning System ForPeoples With Mental Disabillies,Bremen,2010.

22-Maglischo , E, W.,: Swimming fastest, Magfill publishing co, California U.S.A 2003.

23-Waag, Qiyun - Using the Facebook Management System An Exploratory Study British Journal of Education Technology, (2012). 


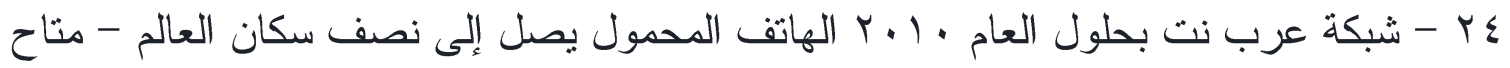

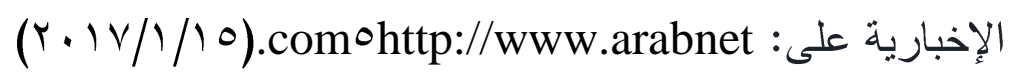

25https//:ar.wikipedia.org/wiki\%/DA\%D\%^r\%१D\%^॰\%१D\%^AD\%D\%^॰\%१

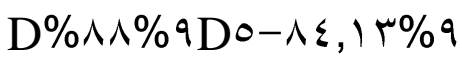

26https://salamatechwiki.org/index.php?title=\%D\%^०\%१D\%^ミ\%१D१

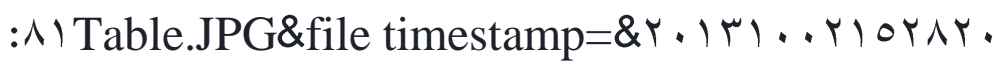

